\title{
Alexandra Laignel-Lavastine, Cioran, Éliade, Ionesco.
} L'oubli du fascisme

Paris, PUF, 2002, 553 p. (coll. « Perspectives critiques »)

Michael Löwy

\section{(2) OpenEdition}

\section{Journals}

Édition électronique

URL : http://journals.openedition.org/assr/2077

DOI : 10.4000/assr.2077

ISSN : $1777-5825$

\section{Éditeur}

Éditions de l'EHESS

Édition imprimée

Date de publication : 1 octobre 2004

Pagination : 53-158

ISBN : 2-222-96754-6

ISSN : 0335-5985

\section{Référence électronique}

Michael Löwy, «Alexandra Laignel-Lavastine, Cioran, Éliade, Ionesco. L'oubli du fascisme », Archives de sciences sociales des religions [En ligne], 128 | octobre - décembre 2004, document 128.26, mis en ligne le 16 novembre 2005, consulté le 21 septembre 2020. URL : http://journals.openedition.org/assr/2077 ; DOI : https://doi.org/10.4000/assr.2077 
qualitatif, celui-ci étant efficace à deux niveaux : tout d'abord, il permet de confronter des phénomènes similaires entre des zones géographiques différentes (la Bretagne et certaines régions de la Suisse et de l'Irlande). Ensuite, il autorise un travail entre les disciplines : l'A. utilise les sciences du langage dont les instruments d'analyse lui semblent encore bien précaires - pour étudier le « Mandement de Carême » à l'aune de la dichotomie entre énoncé et énonciation. Il a également recours, continuellement, à une approche sociologique du fait religieux, justifiée par l'analyse de l'influence de Durkheim, Weber et Troeltsch sur la question, et lui permettant de comparer par exemple la manifestation de rue et le rite de la procession. Ainsi, au fil de ses articles, le lecteur voit le postulat de M.L. s'affermir selon lequel la religion tient un rôle fondamental dans la constitution du lien social.

Dès lors ce n'est plus seulement d'une histoire de l'institution religieuse dont il est question dans l'historiographie moderne mais bien davantage d'une étude de la religion populaire et de son influence dans les mentalités collectives. Durant les périodes de crise, selon l'A., ce sont les dévotions archaïques qui viennent suppléer au défaut de la religion officielle en transcendant les oppositions politiques. En Bretagne par exemple, région souvent marginalisée à cause de la centralisation, le religieux revitalise le lien social par la création d'une contre-société ou d'une subculture. Pour désigner ces réactions sociales spontanées, par lesquelles se forment notamment des bastions catholiques cimentant la population, M.L. emploie une expression pour le moins moderne, celle de « choc religieux ».

Or, le choc, au temps du déclin de la civilisation rurale et de la transformation économique du pays par la technisation, se manifeste aussi dans la création d'alliances inédites entre le religieux et la modernité. Si Garcia Moreno (18211875), président de l'Équateur, est tout à la fois dictateur et saint martyr, l'idée de la confession par téléphone ou la vision du curé de campagne en effraction de vitesse dans une voiture de course a aussi de quoi surprendre. Et ce sont justement ces réalités du monde religieux moderne qu'étudie M.L. : le rôle du sport dans la volonté du catholicisme moderne de retenir les hommes dans la carrière religieuse, l'influence de l'Église dans le développement de la technique, à travers un vulgarisateur scientifique comme le Père Moigno, au XIX ${ }^{\mathrm{e}}$ siècle, ou encore les liens entre le cinéma et le monde catholique. L'opposition philosophique séculaire entre nature et culture retrouve toute son actualité dans les discours entourant par exemple l'invention du bateau à vapeur, tandis que l'intégration de la technique dans le quotidien des hommes religieux est analysée jusque dans les textes canoniques avec, par exemple, l'insertion d'un «benedicto vehiculi seu curus $»$. À cette introduction de certains objets modernes au sein de rites religieux, en l'occurrence la bénédiction de chemins de fer ou d'automobiles, répond la dissolution de l'objet religieux dans l'histoire culturelle via de multiples métaphores telles que «mythes politiques et religions séculières, dieux du stade, du spectacle, de la bande dessinée ». Propres à une époque où s'intensifie l'immigration et se multiplient les rencontres avec «l'autre religieux », ces processus de métaphorisation touchent également les représentations du diable. En effet, au même titre que les nouveautés machinistes de la modernité, la présence d'altérités religieuses différentes du christianisme participe, en Occident, aux « renouvellements successifs de l'Antéchrist et des forces du Mal ».

Ainsi, le présent ouvrage s'ouvre sur un article à vocation confessionnelle où 1'A. y explique son double rapport à la foi et à la science, et s'achève sur une étude du démoniaque, intime à chacun en ses multiples visages. Configuration éditoriale qui, en hommage à M.L., montre bien comment pour ce dernier, l'écriture de l'histoire n'aura été ni une question personnelle ni une réponse objective, mais une recherche nourrie par l'expérience singulière de «l'historien qui, à force de fréquenter les morts, les retrouve vivants derrière la poussière des archives, acquiert une familiarité avec eux. »

Muriel Pic.

\subsection{LAIGNEL-LAVASTINE (Alexandra).}

\section{Cioran, Éliade, Ionesco. L'oubli du fascisme.} Paris, PUF, 2002, 553 p. (coll. «Perspectives critiques »).

Voici un ouvrage impressionnant, par la richesse de sa documentation et la rigueur de ses analyses. Travaillant sur des écrits en langue roumaine inconnus en France et sur des archives jusqu'ici inexploitées, A.L.-L. montre l'ampleur de l'engagement fasciste et antisémite d'Emil Cioran et de Mircea Éliade dans la Roumanie des années 1930 et 1940. Eugène Ionesco ne partageait pas du tout leurs options, mais par une sorte de «solidarité anticommuniste de l'exil», il acceptera de faire le silence sur le passé de ses deux illustres compatriotes. 
C'est surtout le cas de Mircea Éliade qui nous intéresse ici, observé du point de vue des sciences sociales des religions. Au nom d'une « révolution chrétienne », d'une « renaissance spirituelle » et d'une résurrection du «MoyenÂge roumain », l'éminent historien des religions va se rallier au mouvement légionnaire de la Garde de Fer, ouvertement fasciste et antisémite, et responsable, dans les années suivantes, de terrifiants massacres contre les juifs roumains. Il écrira en 1937 un essai «Pourquoi je crois dans la victoire du Mouvement légionnaire », et d'autres textes qui célèbrent les dictatures contre la démocratie, et dénoncent «l'invasion des juifs ». Il ne s'agit pas d'un «péché de jeunesse » éphémère : pendant la Deuxième Guerre mondiale, attaché à l'Ambassade de Roumanie au Portugal, il ne cache pas sa sympathie pour le Troisième Reich, dont il espère, encore en 1943, la victoire contre l'URSS et contre la coalition qu'il désigne comme « anglo-bolchévique ». Dans un ouvrage copieux sur Salazar (1942), il présente ce régime autoritaire et fascisant établi au Portugal comme un modèle exemplaire d' "État totalitaire et chrétien ». Après la guerre, Éliade s'efforcera, avec succès, d'effacer les traces du passé, en niant obstinément ses engagements fascistes ultérieurs.

L'objectif de l'auteur n'est pas de nier l'intérêt des travaux d'histoire des religions d'Éliade, mais de créer les conditions de possibilité d'une lecture de ses œuvres instruite par une meilleure connaissance des dilemmes politiques et culturels qui présidèrent à leur élaboration initiale ainsi qu'à leurs réélaborations ultérieures. Dès 1944 , 1'historien roumain définissait son objectif par la formule suivante : «valider scientifiquement la signification métaphysique de la vie archaïque ». Il a, constate A.L-L, transposé dans la figure de son homo religiosus sa Weltanschuung mystique, élitiste, violente et archaïsante des années 1930. Les catégories religieuses et les conceptions politiques qui poussèrent vers le fascisme et déterminèrent sa fascination pour la mystique de la Garde de Fer sont les mêmes que celles à partir desquelles il bâtit l'univers mental et social de ce qu'il appelle «l'homme archaïque ». L'antisémitisme des écrits politiques se transforme en opposition, thématisée par l'historien des religions, entre le vrai christianisme, cosmique, agraire et primitif, et le judéo-christianisme, qui abandonne le cosmos au profit de l'histoire.

Cet ouvrage remarquable est important non seulement pour ce qu'il nous fait découvrir sur le «cas Éliade », longtemps occulté par une surprenante «amnésie politique », mais aussi par ce qu'il nous révèle, par toute son analyse d'un milieu culturel et d'une génération roumaine des années 1930, du rôle que peut jouer un certain type de religiosité dans certaines formes d'engagement totalitaire.

Michael Löwy.

La République anticléricale, $\mathrm{XIX}^{\mathrm{e}} \mathbf{X X}^{\mathrm{e}}$ siècles. Paris, Seuil, 2002, 475 p. (bibliogr., index, annexes) (coll. «L'Univers historique »).

Ce livre aborde de vastes questions, à commencer par celle que le titre pose d'emblée : la République est-elle, en France, par nature anticléricale ? Du moins, précise l'auteur, en fait de $\mathrm{XIX}^{\mathrm{e}}$ et $\mathrm{XX}^{\mathrm{e}}$, la III $^{\mathrm{e}}$ République, à laquelle l'anticléricalisme donne «sa tonalité particulière », quoique que certaines péripéties évoquées ici nous ramènent à un passé parfois bien plus proche.

Qu'est-ce qu'être anticlérical et qu'est-ce d'abord que le cléricalisme ? Si ce n'est là qu'un autre nom du catholicisme, l'anticléricalisme ne serait dans l'esprit de ceux qui s'en réclament qu'anticatholicisme, ou même guerre déclarée à la religion en tant que telle. Ou bien le terme même dessine-t-il plutôt la délimitation entre la religion catholique et un vrai parti politique, le parti clérical, parti de la contre-Révolution, attaché, comme l'écrivait un historien républicain, à « ruiner le principe de nos lois et de nos institutions »? On pourrait alors isoler ce que l'A. appelle un anticléricalisme « chimiquement pur », c'est-à-dire purement fonctionnel et institutionnel, au titre duquel elle affirme que « la laïcité, quoi qu'on en ait, est obligatoirement anticléricale ». Mais elle relève également que «cléricalisme et anticléricalisme, qui se donnent mutuellement vie, sont deux objets mal délimités », à «géométrie variable », et «dont les contours se déplacent selon le point de vue idéologique qui parle ». Dans un contexte aussi sensible (on dirait aujourd'hui interactif) et mouvant, jusqu'à quel point la distinction estelle vraiment praticable dans les faits?

Les réponses que l'A. propose à ces questions prennent ici la forme d'un recueil d'articles : une série d'interventions qui, de 1989 à 2000, ont accompagné le grand travail sur la Libre pensée par lequel elle comblait une grave lacune de l'historiographie (La Libre pensée en France, 1848-1940, Paris, Albin Michel, 1997). Ces études profitent donc de la connaissance intime que procure une longue pratique tout comme d'une érudition souvent savoureuse.

Le propos n'y est pas de revenir sur les «forces » anticléricales, mais plutôt de tenter 